\title{
A Practical Method for Determining Membership Values In Fuzzy Sets Based on Expert System
}

\author{
Waiel F. Abd El-Wahed and Mohamed Magdy M. El-Farrash \\ Department of Basic Engineering Sciences \\ Faculty of Engineering, El-Minufiya University \\ Shebien El-Kom, Egypt
}

\begin{abstract}
This paper presents a new methodology to estimate the membership values for fuzzy sets. This methodology takes into account the experimental data which reflects the expert knowledge on the relative degree of belonging olf the members to each other in the fuzzy sets. After that the methodology searches for the optimal membership values of the elements by implementing the linear programming model. An illustrative numerical example is given to point out the given methodology.
\end{abstract}

Key Words: Fuzzy sets; Expert knowledge and statistical analysis.

Manuscript received from Dr. Mohamed Magdy M. El-Farrash Accepted on : 19/6/2001

Engineering Research Journal Vol. 24, No. 3, 2001 Minufiya University, Faculty of Engineering, Shebien El-Kom, Egypt, ISSN 1110-1180 
The theory of fuzzy sets (Zadeh [1]) admits the existence of a type of uncertainty due to vagueness (i.e., fuzziness ) rather than due to randomess alone, where classes of objects ( labels of fuzzy sets) have gradual rather than abrupt transition from membership to non-membership.

The philosophy of fuzzy sets can be summarized as"the branch which deals with the hidden parameters which can not be described in the models account in easy marner".

Based on this concept, a membership values are used to characterize their fuzzy sets. there values are given by the decision maker, usually, which may lead to create another hidden information, should be taken into account, and sio on. "This because of the fact which says that the human being mind has no full information about the problem domain although his/her advanced knowledge". So that different researchers directed their attention to find out more practical approaches which can be used for this purpose.

This paper suggest; a practical method based on the expert's knowledge to be used in estimating the membership values. These values are derived from judgment of human expert about the pair wises among the elements of a fuzzy set. A result pair wise judgment matrix is processed by using the Euclidean norm to aggregate each raw in this matrix. The significantly of result values are calibrated by implementing the statistical hypothesis to decide the acceptance or rejection of the extracted expert's knowledge. After that, a linear programing problem is developed based upon the upper and lower bounds of each estimated membership values to determine the optimal membership values.

The paper is organized as follows: Section 2 , presents fuzzy membership function concept and why does it consider ill-structured. Section 3, introduces the suggested approsch and its theoretical basis. It points out the minimization of deviations between the estimated and eiven membership values. 


\section{2- Problem Identification:}

Measurement means weighting objects by assigning numbers to them, such that certain relation between numbers, reflect the relations between objects. Therefore, the properties of the measurement should be consistent with the definition of membership values. Zimmermann, said in his text book [2] that the explicit requirements of the membership values/function empirical/experimental me asurement are still missing and measurement structures have not yet been developed. Based on tris introduction a little bit of prior works have been developed later. For example, Zimmermann [1] introduces two models for determining membership functions. The first is a scale can serve as an operational definition of membership. The second is a specific concept which can help to obtain useful improvement in the estimated membership values.

Other approsches are suggested such as eigenvalues method by saaty [3] Chu et al [4] presented a procedure based on least square methods.

The problem now is : there is a set of objects $S$ and it is required to find a mapping $f: S \longrightarrow A$ (where $A$ is the set of grades) from an empirical stmcture likes an expert system, to assign grades or membership values of these objects.

The answer of this question can be specified through the use of an expert knowledge, i.e., the main idea of this study is how can we implement the philosophy of expert system to support fuzzy analysis ?. The details of the answer will be explained in the next section.

\section{3- Practical Method For Determining Fuzzy Membership Values:}

In this section we are going to point out the implementation of The suggested idea of determining the membership values in a fuzzy set. This implementation is done throughout the following phases:

(a) Knowledge acquisition phase,

(b) Statistical test of the expert's knowledge phase,

(c) Membership values estimation phase, and

(d) A numerical example phase. 
3-a) Knowledge Acquisition phase:

Consider a discrete fuzzy set A defined in a universal set $X$, where $X$ is finite. Let $A(\cdot): X \longrightarrow[1,0]$ be the membership function of the fuzzy set $A, x \in X$. An expert is asked to do pair wise comparison among all $n$ elements in this set $A$. This comparison reflects the relative importance between two elements in the discrete fuzzy set. The expert's judgment are summarized in the following matrix form:

\begin{tabular}{|c|c|c|c|c|c|}
\hline & element (1) & element (2) & $\ldots \cdots$ & element $(n)$ & $\mu^{\prime} s$ \\
\hline element (1) & 1 & $a_{12}$ & $\cdot$ & $a_{1 n}$ & $\mu_{1}$ \\
\hline element (2) & $a_{21}$ & 1 & $\cdot$ & $a_{2 n}$ & $\mu_{2}$ \\
\hline element (3) & & & $\cdot$ & & \\
\hline$\cdot$ & & & $\cdot$ & & \\
\hline \\
\hline
\end{tabular}

Table (1) Expert's knowledge pair wise comparison matrix

Where; in this matrix the comparison of element $i$ with respect to itself is considered 1 . After filling this matrix, the membership of object (i) with respect to other objects can be determined using Euclidear norm as follows:

$$
\mu_{i}=\sqrt{(1)^{2}+\sum_{i=1}^{n} \sum_{j=1}^{n}\left[a_{i, j}\right]^{2}}
$$

The elements of this matxix can be charact erized by the following properties: 


$$
\begin{aligned}
& a_{j i}=1 / a_{i j} \\
& a_{i i}=1 \\
& a_{i j} \neq 0, \forall i, j, i, e,, a_{i j} \geq 1
\end{aligned}
$$

Property $i$, means that the expert's knowledge matrix is a reciprocal matrix, because we are doing a pair wise comparison among the set elements.

3-b) Statistical Test of the Expert's knowledge:

[5], had proved that the extracted numerical information from an expert domain is subjected to statistical t-distribution. From the statistical hypothesis point of view, there are two types of hypothesis. One of them is called the tested hypothesis (HO), while the other is called the alternative hypothesis ( $\mathrm{H} 1)$. According to the statistical analysis, the t-distribution takes the following form:

$$
T_{i}=\frac{\left(M_{i}-\mu_{i}\right) \sqrt{n}}{(S D)_{i}}
$$

where

$T_{i}$ is the standard velue of $\mu_{i}$ under $t$-distribution,

$M_{i}$ is the sample mean of the element $i$,

$$
M_{i}=\frac{\sum_{i=1}^{n} c_{i j}}{n}, j=1,2, \ldots, n,
$$

$\mathrm{n}$ is the number of elements

$\langle S D\rangle_{i}$ is the standard deviation of element $i$,

$$
(S D)_{i}=\left[\frac{\sum_{i=1}^{n} \sum_{j=1}^{n}\left(a_{i j}-M_{j}\right)^{2}}{[n-1]}\right]^{1 / 2}
$$

Under a certain level of significance $\alpha$ and $(n-1)$ degree of freedom, we can easily obtain the values of $\bar{t}_{i}$ and $t_{i}$ from standard table of t-distribution.

If the expert's knowledge is accepted statistically, then 
the process continues to determine the optimal membership values. On the other hand, if the extracted knowledge is rejected statistically, then the problem solver should do feed back with the domain expert to correct the given information.

For each estimated value, the upper and lower bounds are determined as follows:

$$
\text { let } \begin{aligned}
\mu_{i} & =M_{i}-\left(\left(\mathrm{T}_{i} \cdot \mathrm{SD}_{i}\right) / \sqrt{n}\right) \\
\therefore \mu_{i} & =\left|\left(\mathrm{T}_{i} \cdot \mathrm{SD}_{i}\right) / \sqrt{n}\right|
\end{aligned}
$$

Based on the curve of t-distribution

$$
\begin{aligned}
\therefore \bar{\mu}_{i} & =M_{i}+\Delta_{i} \\
\mu_{i} & =M_{i}-\Delta_{i}
\end{aligned}
$$

$\bar{\mu}_{i}$ and $\mu_{i}$ are upper and lower bounds of $\mu_{i}$ respectively 3-c) Membership values Estimation:

In this subsection, a linear programming model is developed to determine the membership values of of elements in a fuzzy set as follows:

Let $\beta$ be an arbitrary auxiliary variable

$$
\begin{aligned}
& \text { (LP): } \quad \begin{array}{l}
\text { Min } \beta \\
\text { s.t. } \\
\mu_{i} \leq \mu_{i} \leq \bar{\mu}_{i} \\
\\
\sum_{i=1}^{n} \mu_{i}=1 \\
0<\mu_{i} \leq 1 \forall i, i=1,2, \ldots, n \\
\beta \geq 0
\end{array}
\end{aligned}
$$

In (LF) model, constraint (9) represents the range of each $\mu_{i}, i=1,2, \ldots, n$. Constraint (10), is responsible for normalizing the resultant membership values since $\mu_{i}$ should satisfied condition no. (11). This model can be solved by using 
any computer package to get the optimal membership values of the elements in a discreet fuzzy set.

The steps of the methodology can be summarized as follows:

Step_ I Interact with an expert domain to construct the expert's knowledge pair wise comparison matrix.

Step_z Apply the Euclidean norm (equ. 1) to aggregate the information of each row. Consider these are initial values.

Step_3 Apply t-distribution to check the significancy of each estimated value. If it is accepted, go to step (4). Otherwise, go to step (1).

Step 4 Determine the upper and lower bounds of each estimated value by using Equations (6) and ( 7 ).

Step 5 Apely (LP) model to find the optimal membership values.

Step_B Stop.

\section{3-d) A numerical Example:}

Let a fuzzy set has 4 elements and the expert"s knowledge matrix is extracted and constructed as follows:

\begin{tabular}{|l|l|l|l|l|l|}
\hline \multicolumn{1}{c|}{} & $E_{1}$ & $E_{2}$ & $E_{3}$ & $E_{4}$ & $\mu_{i}$ \\
\hline$E_{1}$ & 1 & 3.6 & 2.2 & 0.5 & 4.36 \\
\hline$E_{2}$ & 0.28 & 1 & 0.78 & 3.1 & 3.36 \\
\hline$E_{3}$ & 0.45 & 1.28 & 1 & 2 & 2.62 \\
\hline$E_{4}$ & 2 & 0.32 & 0.25 & 1 & 2.27 \\
\hline
\end{tabular}

The calculated statistical parameters of this data are summarized in the following table: 


\begin{tabular}{|l|c|c|c|c|c|}
\cline { 2 - 6 } \multicolumn{1}{c|}{} & $\mathrm{M}_{i}$ & $(\mathrm{SD})_{\mathrm{i}}$ & $(\mathrm{n}-1)$ & $\alpha$ & $\mathrm{T}_{i}$ \\
\hline element (1) & 1.825 & 1.382 & 3 & 0.95 & 2.1407 \\
\hline element (2) & 1.29 & 1.2437 & 3 & 0.95 & 1.9603 \\
\hline element (3) & 1.1825 & 0.645 & 3 & 0.95 & 3.0226 \\
\hline element (4) & 0.8925 & 0.8121 & 3 & 0.95 & 1.7546 \\
\hline
\end{tabular}

From the table of t-distribution, at $(n-1)$ degree of freedom and level of significance $=0.05$, it was found that the extracted knowledge matrix is accepted statistically.

$$
\begin{array}{ll}
\Delta_{1}=1.626, & \underline{\mu}_{1}=0.1991,
\end{array}
$$

The LP model is as follows:

$$
\begin{aligned}
& \text { Min } \beta \\
& \text { s.t. } \\
& 0.1991 \leq \mu_{1} \leq 3.451 \\
& 0.1732 \leq \mu_{2} \leq 2.753 \\
& 0.4237 \leq \mu_{3} \leq 1.9413 \\
& 0.0629 \leq \mu_{4} \leq 1.8479 \\
& \mu_{1}+\mu_{2}+\mu_{3}+\mu_{1}=1 \\
& \mu_{:}: 0 \\
& : \geq 0
\end{aligned}
$$

The wiwled is solved by stom package and the results are:

$$
\mu_{1}=0.3402, \quad \mu_{2}=0.1 \% 2, \quad \mu_{3}=0.4237, \quad \mu_{1}=0.0629
$$


Conclusion:

This paper has suggested a methodology based on both statistical analysis and linear programing to estimate the membership values of a discrete fuzzy set. The methodol o gy is easy applied and appears to have a reasonable estimation results with sufficiency low time.

REEERENCES

[1] L. A. Zadeh (1965), Fuzzy Sets, Information And Control Vol. 8, pp. 338-353.

[2] H.J. Zimmermann, 1985, "Fuzzy Set Theory And its Applications", Kluwex-Nijhoff, Boston.

[3] Makarov, Z., Vinnograd Skaya, T. M., Rubchinsky, A. A. and Sokolov, V. B., 1987, "The theory of choice and Decision making". English Translation copy, Mir publisher, moscow, USSR.

[4] A. T. W. Chu, R. E. Kalaba, k. Spingarn, "A Comparison of two methods for determining the weights of belonging to fuzzy sets, J. optim. Theory Appl., 27, 1979, pp. $531-538$.

[5] T. L. Saaty, "Exploring the interf ace between hierarchies, Multiple objectives and fuzzy sets, Fuzzy sets and systems, 1, 1978, pp. 57-68: 
طريقة عملية لتعيين قيم العضوية في الفئات الفازية معتمدة علي خحبرة الحبير

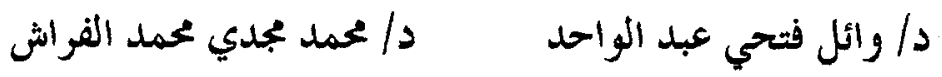

$$
\begin{aligned}
& \text { قسم العلوم الأساسية المندسية كلية المندسة بشبين الكوم }
\end{aligned}
$$

\section{ملنص البحث}

يقدم هذا البحث طريقة عملية جديدة لحساب قيم العضوية في الفئات الفازية. و وهذه الطريقة تــأحذ في الاعتبار البيانات العملية حول عناصر الفئة الفازية والتي تعكس خبرة الخبير حول أهمية كل عنصر بالنسبة للآخر في الفئة الفازية المعرفة. بعد ذلك يتم اختبار هذه البيانات إحصائيا لمعرفة قبولما أو رفضها. وفي حالة قبولها يتم بناء نـــوذج بربخة خطية لحساب قيم العضوية المثلى. وفي حالة رفضها يتم عمل تغذية خلفية مع الحبير لتعديسلـل البيانات. رقد قدم البحث مثالا عدديا لتوضيح كيفية تطبيق هذه الطريقة. 